\title{
Zooterapia popular na Chapada Diamantina: uma medicina incidental?
}

\author{
Folk medicine using animals in the Chapada Diamantina: \\ incidental medicine?
}

Flávia de Barros Prado M oura ${ }^{1}$

JoséGeraldo Wanderley M arques ${ }^{2}$

${ }^{1}$ ICBS, Universidade Federal deAlagoas. RuaAristeu de Andrade 452, Farol. 57051-090 Maceió AL. flavia.moura@ pesquisador. cnpq.br ${ }^{2}$ Laboratório de

Etnoecologia, Departamento de Biologia, U niversidade Estadual deFeira deSantana.

Abstract This study examines the traditional therapeutic use of animals or parts of animals by an Afro Brazilian population living in the Chapada Diamantina, Bahia, Brazil. The investigation was conducted over a period of eight months and consisted of open- and semi-structured interviews, photographic documentation and identification of species. Besides presenting a list of animal products and their respective use, we seek to stimulatea discussion about the possible existence of a rational basis for the belief in the therapeutic or prophylactic potential of the animal products used in the traditional medicine of Brazilian populations.

Key words Folk medicine, Indigenous populations, Ethnomedicine
Resumo Este trabalho analisa o sistema zooterápico tradicional de uma população afrodescendente na Chapada Diamantina, Bahia. A pesquisa foi conduzida ao longo de oito meses de trabalho nos quais foram realizadas entrevistas livres e semiestruturadas, registro fotográfico e identificação deespécies. Busca-se, além da apresentação deuma lista de produtos oriundos de animais e seus respectivos usos, iniciar uma discussão sobre as possíveis razões para crença no potencial terapêutico ou profilático das frações e produtos animais amplamente utilizados na medicina tradicional de populações brasileiras.

Palavras-chave Medicina popular, Zooterapia, Populações tradicionais, Etnomedicina 
O saruê foi o único animal que ajudou N ossa Senhora dando leite para o M enino Jesus. Aí ela disse: vocêvai parir sem dor. Não tem nada melhor do que o couro do saruê para apressar o parto.

\section{Introdução}

O uso de animais na medicina popular é um fe nômeno amplamente distribuído do ponto de vista histórico e geográfico, que vem sendo estudado sob diferentes abordagens - etnográficas ${ }^{1,2}$, médicas $^{3}$, farmacológicas ${ }^{4}$ e ecológicas $s^{5-9}$.

Toda civilização, para desenvolver seu sistema médico, exercita a prática da observação e a caracterização empírica dos fenômenos. Provavelmente, muitos produtos obtidos de animais e plantas foram incorporados à farmacopéia popular por acaso, pela avaliação dos sintomas experimentados após o consumo, assim como muitos podem ter sido incluídos ou eliminados após seqüências de tentativas e erros.

N estetrabal ho, o sistema zooterápico de uma população afrodescendente na Chapada Diamantina é analisado. Busca-se, além da apresentação de uma lista de produtos oriundos de animais e seus respectivos usos, iniciar uma discussão sobre as possíveis razões para a crença no potencial terapêutico ou profilático das fraçõese produtos animais amplamente utilizados na medicina tradicional de populações brasileiras.

\section{M etodologia}

O trabalho de campo foi conduzido no povoado do Remanso, no município de Lençóis, Bahia. A população de 206 habitantes é composta predominantemente de afrodescendentes quevivem da pesca e da agricultura familiar e, mais recentemente, do turismo.

Nos três meses iniciais de trabalho, foram visitadas vinteresidências $(60 \%)$, buscando identificar usos e formas de uso de partes ou produtos animais. Foi utilizada nesta etapa a metodologia geradora de dados ${ }^{10}$, que se baseia em perguntas abertas. As entrevistas iniciais permitiram a identificação de cinco especialistas locais com idades variando de 23 a 65 anos, entre os entrevistados ou apontados por estes. Foram consideradas especialistas locais pessoas reconhecidas pela população como os principais detentores do conhecimento sobre a prática zooterápica tradicional. N os cinco meses seguintes, com cada um dos especialistas, foram realizadas de uma a cin- co entrevistas semi-estruturadas com duração de 20 a 50 minutos. As entrevistas tiveram como objetivo aprofundar o conhecimento sobre o sistema médico local.

Para a sistematização dos dados, foi usado o modelo da união das diversas competências ${ }^{11}$. Foi efetuado o registro fotográfico de frações animais utilizadas com fins terapêuticos encontradas nas residências (Figuras 1 e 2 ). A identificação das espécies foi feita a partir de pistas taxonômicas fornecidas pela população local e consulta à bibliografia especializada.

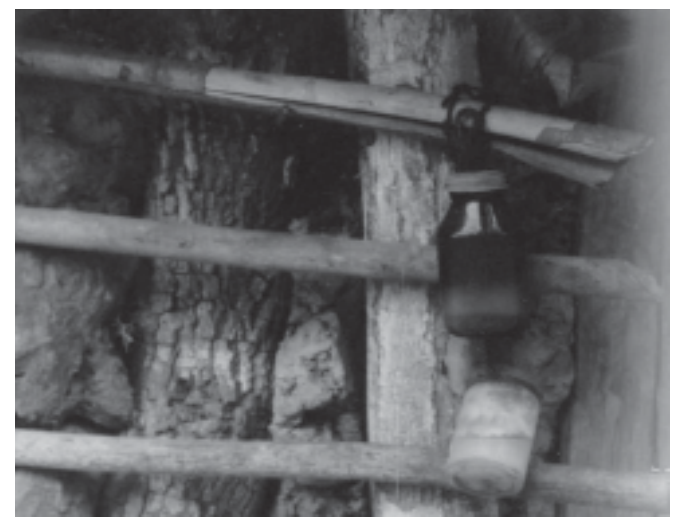

Figura 1. Farmácia caseira: gorduras de animais, encontradas em uma residência do povoado do Remanso.

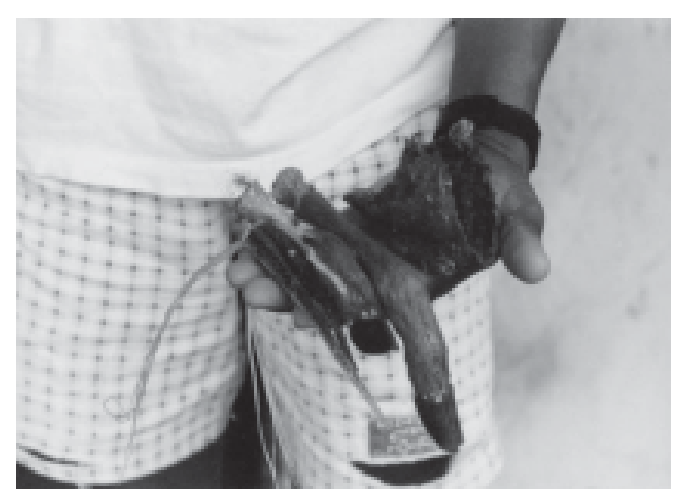

Figura 2. Farmácia caseira: frações animais usadas com finalidades terapêuticas encontradas em uma residência do povoado do Remanso. 


\section{Resultados}

0 uso de animais na medicina local parece bastante amplo, tendo sido obtida uma lista com 52 espécies de animais (Quadro 1), as quais fornecem 72 matérias-primas para prevenção ou tratamento de 39 enfermidades. As gorduras se destacaram como o principal produto medicinal, tendo sido mencionadas como úteis gorduras de 19 dos 52 animais que fazem parte do receituário.

Além destas, são utilizadas outras partes e produtos como: casco, pêlo, vísceras, espinhos, chifres, couros, dentes, ninhos, fezes, leite emel. 0 número de partes ou produtos obtidos de cada animal variou de um a três. Alguns animais, entretanto, são usados integralmente, podendo ser torrados, moídos, transformados em pó eadicionados a chás ou misturados a alimentos.

$\mathrm{Na}$ medicina popular do Remanso, como em muitas outras populações tradicionais brasileiras, a obtenção e manutenção da saúde envolvem práticas terapêuticas nas quais a função médica ou litúrgica dos recursos se confunde ${ }^{12-15}$. A cren- ça no potencial terapêutico de um animal pode se dever a uma grande variedade de fatores que vão do plano físico, como a avaliação dos sintomas experimentados após o seu consumo, ao simbólico, como associação da forma da fração animal utilizada à parte do corpo humano que requer cuidados.

Três características, entretanto, isoladas ou combinadas, mostraram-se recorrentes. Animais, suas frações ou produtos considerados medicinais: 1) têm, segundo a crença local, o potencial de provocar alteração da temperatura corpórea ( propriedade de aquecer ou resfriar o corpo do usuário); 2) têm uma morfologia que pode ser associada à parte do corpo humano que precisa ser tratada; e/ou 3) não têm utilidade para outros fins. Estas características, aparentemente, não são exclusivas dos zooterápicos usados pela população estudada, podendo se constituir uma base comum com modelos médicos de outras populações brasileiras. Nas sessões a seguir, discutiremos esses possíveis padrões, buscando explicações aplicáveis, pelo menos, à população estudada.

Quadro 1. Animais que compõem o repertório zooterápico do Remanso, sua possível identificação taxonômica, parte utilizada e finalidade. N este último caso, optou-se por adotar o termo local para a enfermidade e, quando possível, sua equivalência seguida do símbolo (?). Ressalta-se a dificuldade em traduzir categorias locais para categorias aceitas na medicina convencional uma vez que muitos problemas de saúde não encontram correspondência 1/1 com a medicina oficial.

\begin{tabular}{|l|l|l|l|}
\hline Nome popular & \multicolumn{1}{|c|}{ Pista taxonômica } & \multicolumn{1}{c|}{ Parte ou produto } & \multicolumn{1}{c|}{ Finalidade } \\
\hline abelha & Apis mellifera & $\begin{array}{l}\text { mel } \\
\text { ninho }\end{array}$ & $\begin{array}{l}\text { gripe } \\
\text { disenteria }\end{array}$ \\
\hline andorinha & Hirundinidae & pena & avexado= problemas neurológicos (?) \\
\hline anu preto & Crotophaga ani & banha & reumatismo \\
\hline araponga & Procnias nudicollis & carne & tuberculose \\
\hline arapuá & Trigona spinipes & $\begin{array}{l}\text { mel } \\
\text { ninho }\end{array}$ & $\begin{array}{l}\text { fortificante } \\
\text { sinusite } \\
\text { gripe }\end{array}$ \\
\hline aruá & Pomacea sp. & desova & inchação=edemas \\
\hline besouro & Hymenoptera & ninho & $\begin{array}{l}\text { surdeza=dificuldade deaudição (?) } \\
\text { papeira=parotidite (?) }\end{array}$ \\
\hline boi & Bos taurus & moela (benzoá ?) & picada de cobra \\
\hline cachorro & Canis familiaris & fezes & sarampo \\
\hline cágado & Phrynops geoffroanus & $\begin{array}{l}\text { carne } \\
\text { casco }\end{array}$ & $\begin{array}{l}\text { reumatismo } \\
\text { botando as tripas=prolapso retal (?) }\end{array}$ \\
\hline cancão & Cyanocorax cyanopogon & avexado=problemas neurológicos (?) \\
\hline
\end{tabular}


Quadro 1. continuação

\begin{tabular}{|c|c|c|c|}
\hline Nome popular & Pista taxonômica & Parte ou produto & Finalidade \\
\hline capivara & Hidrochaeris hidrochaeris & $\begin{array}{l}\text { osso } \\
\text { casco } \\
\text { bílis }\end{array}$ & derrame=AVC (?) \\
\hline cascaveio & Crotalus durissus & $\begin{array}{l}\text { banha } \\
\text { língua } \\
\text { chocalho }\end{array}$ & $\begin{array}{l}\text { reumatismo } \\
\text { picada de cascavel } \\
\text { proteção contra picada de cobra }\end{array}$ \\
\hline catitu & Tayassu sp. & $\begin{array}{l}\text { banha } \\
\text { bucho }\end{array}$ & $\begin{array}{l}\text { reumatismo } \\
\text { puxado=asma }\end{array}$ \\
\hline cigarra & Cicadidae & exoesqueleto & surdeza=dificuldade de audição (?) \\
\hline cumbá & Parauchenipterus galeatus & esporão & homem nojento=impotência \\
\hline galça & Casmerodius albus & banha & bronquite/pneumonia \\
\hline galinha/galo & Gallus gallus & banha & bronquite/pneumonia \\
\hline grilo & Gryllus sp. & perna & urina presa=infecção urinária (?) \\
\hline jabuti & Geochelone carbonaria & $\begin{array}{l}\text { carne } \\
\text { casco }\end{array}$ & $\begin{array}{l}\text { reumatismo } \\
\text { botando as tripas=prolapso retal (?) }\end{array}$ \\
\hline jacaré & Caiman latirostris & $\begin{array}{l}\text { banha } \\
\text { dente }\end{array}$ & $\begin{array}{l}\text { reumatismo } \\
\text { dente=facilitar nascimento da } \\
\text { dentição em crianças }\end{array}$ \\
\hline jacaré de mata & Paleosuchus palpebrosus (?) & couro & doença do vento=AVC (?) \\
\hline jacú & Cracidae sp. & banha & dor de ouvido \\
\hline jibóia & Boa constrictor & banha & reumatismo \\
\hline jitaí & Tetragonisca angustula & mel & vilide=leucoma(?) \\
\hline lagartixa & Tropidurus torquatus & corpo inteiro & ferida que não sara (?) \\
\hline lesma & $\ldots$ & corpo & $\begin{array}{l}\text { rachadura no pé } \\
\text { asma }\end{array}$ \\
\hline mandaçaia & M elipona quadrifasciata & mel & fortificante \\
\hline piau & Leporinus piau & banha & reumatismo \\
\hline piranha & Serrasalmus brandtii & fel & amarelidão de neném= icterícia (?) \\
\hline raposa & Cerdocyon thous & banhacouro & dor de colunadoença do vento=AVC \\
\hline rolinha & $\ldots$ & sangue da cabeça & surdeza=problemas de audição \\
\hline salamanta & Epicrates cenchria & banha & reumatismo \\
\hline sapo & Bufo sp. & corpo inteiro & ferida que não sara \\
\hline saruê & Didelphis sp. & $\begin{array}{l}\text { banha } \\
\text { escroto }\end{array}$ & $\begin{array}{l}\text { dores no corpo } \\
\text { reumatismo } \\
\text { facilitar o parto }\end{array}$ \\
\hline sucuiu & Eunectes murinus & banha & reumatismo \\
\hline SOcó & Tigrisoma lineatun & banha & bronquite/pneumonia \\
\hline teiú & Tupinambis merianae & $\begin{array}{l}\text { banha } \\
\text { casco }\end{array}$ & $\begin{array}{l}\text { reumatismo } \\
\text { picada de cobra } \\
\text { doença do vento=AVC (?) }\end{array}$ \\
\hline traíra & H oplias lacerdae & banha & $\begin{array}{l}\text { reumatismo } \\
\text { vilide=leucoma (?) }\end{array}$ \\
\hline urubú & Coragyps atratus & $\begin{array}{l}\text { banha } \\
\text { crista }\end{array}$ & $\begin{array}{l}\text { gripe } \\
\text { fortificante }\end{array}$ \\
\hline uruçu & Melipona scutellaris & mel & $\begin{array}{l}\text { gripe } \\
\text { sinusite } \\
\text { dor-de-cabeça }\end{array}$ \\
\hline zabelê & Crypturelus noctivagus zabele & sangue da cabeça & surdeza=problemas de audição (?) \\
\hline
\end{tabular}


A propriedade de provocar alteração da temperatura corpórea: uma medicina humoral (re) inventada?

No sistema médico do Remanso, dos 39 problemas de saúde relatados, 17 tiveram suas causas atribuídas a excesso de exposição ao frio ou ao calor. Doenças como reumatismo, além daquelas relacionadas ao aparelho respiratório (asma, bronquite, tuberculose), são freqüentemente associadas à exposição excessiva a temperaturas frias. 0 excesso de calor provocaria inflamações oftálmicas, problemas dermatológicos, neurológicos, cólicas, gases, diarréias e outros problemas relacionados ao aparelho digestório (Quadro 2).

Os termos "fresco" e "quente" são popularmente associados a produtos de origem animal ou vegetal, capazes de aquecer ou resfriar o corpo dos usuários, segundo a crença local. A forte crença popular de que muitas enfermidades são causadas por exposição excessiva ao frio ou ao calor faz com que, freqüentemente, se pratique o uso de alimentos ou medicamentos com possíveis propriedades antagônicas na tentativa de se restabelecer a temperatura adequada e, conseqüentemente, a saúde.

Quadro 2. Administração de animais segundo a lógica do sistema de oposição binária quente x frio.

\begin{tabular}{|c|c|c|c|c|c|}
\hline \multirow[t]{2}{*}{ Indicação } & \multirow[t]{2}{*}{$\begin{array}{l}\text { Animais (partes e } \\
\text { produtos) indicados }\end{array}$} & \multicolumn{2}{|c|}{$\begin{array}{c}\text { Causas atribuídas } \\
\text { à doença }\end{array}$} & \multirow[t]{2}{*}{ Informação local } & \multirow[t]{2}{*}{$\begin{array}{c}\text { Justificativa (?) segundo } \\
\text { o sistema dual }\end{array}$} \\
\hline & & calor & frio & & \\
\hline $\begin{array}{l}\text { doença do vento/ } \\
\text { derrame = AVC }\end{array}$ & couro da raposa & $x$ & & $\begin{array}{l}\text { "Tem que dar um } \\
\text { defumador que faz a } \\
\text { pessoa suar. Na hora que } \\
\text { está trocendo a boca faz o } \\
\text { defumador e abafa". }\end{array}$ & $\begin{array}{l}\text { O “derrame” tem sua causa } \\
\text { atribuída ao fato de uma pessoa } \\
\text { suada se expor a uma corrente de } \\
\text { vento. O calor devolveria ao corpo } \\
\text { a temperatura normal. }\end{array}$ \\
\hline $\begin{array}{l}\text { dor de cabeça } \\
\text { disenteria }\end{array}$ & mel de abelha & $X$ & & $\begin{array}{l}\text { "O mel de jataí é o mel } \\
\text { mais fresco que tem". } \\
\text { Idem }\end{array}$ & $\begin{array}{l}\text { A dor de cabeça tem como causa } \\
\text { principal o excesso de sol recebido } \\
\text { durante o trabalho nas roças. } \\
\text { A disenteria e outros problemas } \\
\text { digestivos têm causas atribuídas ao } \\
\text { calor. }\end{array}$ \\
\hline dor de coluna & banha de jibóia & & $x$ & $\begin{array}{l}\text { "No tempo de friagem a } \\
\text { pessoa sente mais (dor), } \\
\text { aí pega essas banhas, essa } \\
\text { mesma de jibóia e passa } \\
\text { morna". }\end{array}$ & $\begin{array}{l}\text { Dores de coluna, no corpo, assim } \\
\text { como reumatismo manifestam-se } \\
\text { predominantemente durante a } \\
\text { estação fria. }\end{array}$ \\
\hline dor nos peitos & banha de galinha & & $x$ & $\begin{array}{l}\text { "Passa a banha morna e } \\
\text { depois não pode pegar } \\
\text { vento". }\end{array}$ & Idem anterior. \\
\hline $\begin{array}{l}\text { fraqueza de } \\
\text { homem = } \\
\text { impotência }\end{array}$ & esporão do cumbá & & $x$ & $\begin{array}{l}\text { "O cumbá não pode ser } \\
\text { comido por todo mundo. } \\
\text { Ele é muito quente. É } \\
\text { comendo ele e dando } \\
\text { uma suadeira. É o viagra } \\
\text { natural". }\end{array}$ & $\begin{array}{l}\text { Aos alimentos de difícil digestão } \\
\text { considerados quentes atribuem-se } \\
\text { propriedades de fortalecer e/ou } \\
\text { aquecer o corpo. }\end{array}$ \\
\hline reumatismo & banha da cascavel & & $x$ & $\begin{array}{l}\text { "A pessoa fica com } \\
\text { reumatismo de tanto } \\
\text { tomar friagem pescando } \\
\text { nesse rio. O remédio é a } \\
\text { banha da cascavel". }\end{array}$ & $\begin{array}{l}\text { Reumatismo tem causa atribuída } \\
\text { ao excesso de frio recebido durante } \\
\text { a pescaria. A banha da cascavel } \\
\text { morna pode aquecer o corpo. }\end{array}$ \\
\hline vilide = leucoma? & banha da traíra & $X$ & & $\begin{array}{l}\text { "É muito fresco; a traíra } \\
\text { é o peixe mais manso que } \\
\text { tem. Ele não ofende a } \\
\text { ninguém". }\end{array}$ & $\begin{array}{l}\text { Problemas oftálmicos têm causa } \\
\text { atribuída ao excesso de calor. A } \\
\text { traíra é um peixe considerado } \\
\text { fresco. }\end{array}$ \\
\hline
\end{tabular}


Fortemente arraigada na medicina popular contemporânea, a crença de que muitas doenças estariam relacionadas ao desequilíbrio entretemperaturas corporais já teve lugar privilegiado na história da medicina ocidental: remonta à medicina humoral, atribuída a Hipócrates (460-375 a.C.). Hipócrates adicionou à teoria dos quatro elementos de Empédocles (504-443 a.C.) quatro qualidades (frio, calor, seco e molhado), associadas aos quatro humores (sangue, fleuma, bile negra e bile amarela). A saúde, assim como a personalidade, provinha do equilíbrio entre esses humores opostos ${ }^{16-18}$. A medicina oriental também postula que o corpo necessite manterse equilibrado com o ambiente para garantir seu funcionamento harmônico. Para a medicina tradicional chinesa, o comprometimento deste equilíbrio é responsável por doenças ${ }^{19}$.

Na medicina popular, o conceito de equilíbrio, particularmente no que se refere ao sistema quente/frio, é bastante difundido entre diferentes povos, tendo sido referido por diversos autores para sistemas médicos de populações do novo mundo ${ }^{12-17,20,21}$. Voeks ${ }^{15}$ reporta o sistema quente/frio caracterizando divindades do candomblé, embora argumente que não há evidências de que as raízes deste sistema dual provenham do continente africano. 0 autor referido, com base em estudos realizados com povos da América Central e povos indígenas isolados na América do
Sul, sugere que o sistema tenha-se produzido de forma endógena (no novo e no velho mundo), evoluindo independentemente. A origem independentejustificar-se-ia, possivelmente, pela capacidade de percepção de alterações no corpo, quando este é submetido a excessos, principalmente no que se refere às sensações físicas de frio e calor. Outra possibilidade, embora meramente especulativa, seria a de que a teoria proposta por H ipócrates e popularizada por Galeno, quevigorou até o século XVIII, tenha sido amplamente disseminada, deixando marcas em sistemas mé dicos de populações distintas que, embora se utilizando de produtos diversos, abandonando, substituindo ou incorporando novos produtos, fundamentem-se em bases teóricas semelhantes, trazidas e mantidas com as populações migrantes durante mais de dois séculos.

\section{A natureza mostra a cura: a teoria das assinaturas (re) descoberta?}

O segundo critério utilizado no Remanso para justificar o uso de uma fração animal ou de seu corpo inteiro é a sua forma semelhante a um órgão ou parte do corpo que requer cuidados. $\mathrm{A}$ semel hança morfológica éfreqüentementeinterpretada como a sugestão de um benefício potencial (Quadro 3).

Quadro 3. Exemplos da administração de partes e produtos de animais, de acordo com a "teoria das assinaturas".

\begin{tabular}{|c|c|c|c|}
\hline Indicação & $\begin{array}{l}\text { Animais (partes e } \\
\text { produtos) }\end{array}$ & Informação local & $\begin{array}{l}\text { Justificativa (?) de acordo } \\
\text { com a teoria das assinaturas }\end{array}$ \\
\hline $\begin{array}{l}\text { fraqueza }= \\
\text { impotência }\end{array}$ & cumbá & $\begin{array}{l}\text { "Porque o cumbá é um peixe de } \\
\text { muita ciência: o macho de todos } \\
\text { viventes só tem dois bagos, ele } \\
\text { tem uma penca." }\end{array}$ & $\begin{array}{l}\text { Atribuem à capacidade de excitação } \\
\text { sexual masculina, ao fato do peixe } \\
\text { apresentar testículos franjados e } \\
\text { volumosos. }\end{array}$ \\
\hline parto difícil & $\begin{array}{l}\text { capanga do saruê }= \\
\text { couro do escroto }\end{array}$ & $\begin{array}{l}\text { "O saruê foi o único animal que } \\
\text { ajudou N ossa Senhora dando leite } \\
\text { para M enino Jesus. Aí ela disse: } \\
\text { você vai parir sem dor. Não tem } \\
\text { melhor do que o couro dele para } \\
\text { apressar o parto; pode o menino } \\
\text { está atravessado..." }\end{array}$ & $\begin{array}{l}\text { O fato de o saruê ser um marsupial } \\
\text { sugere que ele não apresente dor ou } \\
\text { dificuldades na hora do parto; seria, } \\
\text { portanto, indicado para apressar o } \\
\text { parto difícil. }\end{array}$ \\
\hline reumatismo & banha da cascavel & $\begin{array}{l}\text { "Passa ela, esfrega e depois não } \\
\text { pode sair no sereno. Só serve se a } \\
\text { cobra ficar esticada depois que } \\
\text { morrer. Se a cobra se envergar } \\
\text { não adianta pegar a banha, pois a } \\
\text { pessoa fica mais envergada ainda". }\end{array}$ & $\begin{array}{l}\text { Associa-se a forma do animal morrer } \\
\text { (curvo ou reto) para conferir a sua } \\
\text { utilidade. }\end{array}$ \\
\hline
\end{tabular}


0 uso direto ou indireto de frações ou órgãos de animais devido a características morfológicas é recorrente na medicina popular brasileira. Os exemplos mais comuns são os amule tos, os quais são usados para atrair o sexo oposto, aumentar o desempenho sexual, prevenir mau-olhado, entre tantas outras funções. Um caso bem ilustrativo é o uso, em diferentes regiões do Brasil, do dente de jacaré para facilitar o nascimento de dentes em crianças. $N$ este caso, 0 uso podeser direto - torrado eadicionado à água de beber - ou indireto - portado como amuleto ${ }^{6}$. 0 escroto do saruê (um marsupial) é usado no Remanso para apressar o parto; o pênis do quati (N asua nasua), usado no Remanso contra impotência, teve o mesmo uso registrado em Alagoas ${ }^{6}$; a genitália do boto (Inia geoffrensis) éusada na Amazônia brasileira e teria a função de atrair o sexo oposto ${ }^{2,4}$, amparada, provavelmente, na mesma lógica.

0 uso de produtos devido a critérios morfológicos nos remete à teoria das assi naturas (Signatura Rerum), atribuída a Paracelso (14951541). A teoria das assinaturas preconiza quetudo que a natureza cria recebe a imagem da virtude que ela pretende esconder. Assim, plantas e animais exibiriam morfologia, bem como cores ou odores, que pudessem ser relacionados à parte do corpo humano que mereceria cuidados. As características exibidas seriam uma maneira de sinalizar, para a humanidade, as suas propriedades terapêuticas. Completamente desprovida de base científica, a crença parece sobreviver na cultura popular por mais de cinco séculos.

Remédio ou lixo: uma medicina das sobras reencontrada?

Uma terceira característica comum em frações de animais, ou mesmo em animais intei ros usados como medicinais, é a sua inutilidade para outros fins. M ais da metade ( $55 \%$ ) das frações/ produtos utilizados no Remanso são subprodutos de animais. Embora estudos sobre a zooterapia popular brasileira ainda não tenham se voltado para a análise quantitativa de uso de sobras ou subprodutos animais, a prática é bem documentada em listagens de zooterápicos obtidas com populações tradicionais em diferentes estados do Brasi |1,2,4-7,22,23. Essa prática já havia sido observada por $\mathrm{H}_{0}$ landa ${ }^{24}$ para a primeira metade do século XX, quando 0 autor relata 0 uso, como amuletos e remédios, de partes de animais silvestres consideradas impróprias para a alimentação ou manufatura de couros, afirmando que a utilidade medicinal destas partes era bastante arraigada na mentalidade popular da época. Cita, entre as partes passíveis de uso, os chifres, os dentes, as unhas, os ossos, os cascos, as couraças e as gorduras.

No caso particular da comunidade do Remanso, é possível sugerir, cautelosamente, três vias explicativas para o uso de sobras ou subprodutos na medicina popular: a primeira de cunho socioeconômico, a segunda decunho ecológico e a terceira de cunho farmacológico.

A primeira possibilidade seria a de que, sendo formadas por pessoas economicamente excluídas (descendentes de escravos), o uso de sobras teria emergido historicamente tendo como base as sobras alimentares da classe dominante, ou seja, partes desprezadas, sem valor comercial, disponíveis como matéria prima.

Do ponto de vista da teoria ecológica, o uso de sobras poderia ser justificado como uma tentativa de maximizar os recursos obtidos dos ecossistemas locais, uma vez que a maioria das partes medicinais - chifres, couros, escamas - são impróprias para consumo alimentar devido à dificuldade mecânica para sua ingestão. Assim, a população estaria maximizando o que retira da natureza, utilizando como medicamento partes que, apresentando dificuldades para serem usadas na alimentação diária, seriam descartadas.

Pela via explicativa de cunho farmacológico, a hipótese seria que, em pelo menos alguns desses subprodutos, concentrem-se substâncias bioativas de efeito medicinal, as quais, se ingeridas em proporções compatíveis com os objetivos alimentares, teriam efeito deletério sobre 0 organismo dos seus consumidores - daí a sua exclusão do cardápio ea sua inclusão na farmacopéia. Esta explicação talvez possa ser aplicada não só a frações animais, como também a animais inteiros, cujos espécimes, se consumidos em quantidades compatíveis com os objetivos alimentares, pudessem provocar reações indesejáveis (e. g., tóxica, alérgica, etc.). Estas reações poderiam incidir, de forma particular, sobre o organismo de pessoas em estados especiais (e. g., doentes, convalescentes, gestantes ou durante puerpério e pósoperatório) e daí a restrição dietética.

As três possibilidades aqui aventadas para explicar o uso de sobras talvez não se apliquem exclusivamente à população estudada, uma vez que o fenômeno do uso de sobras/subprodutos aparenta ser amplo e talvez se constitua numa das características mais marcantes na zooterapia popular brasileira. 
Do popular científico

ao científico popular: considerações finais

Um dos objetivos das pesquisas sobre o conhecimento tradicional é a busca das possibilidades de integrá-lo ao conhecimento acadêmico e uma das estratégias para fazê-lo é gerar hipóteses testáveis. Tal abordagem tem se revelado frutífera para a obtenção de novos medicamentos ${ }^{25}$. Wilson ${ }^{26}$ salienta que o estudo do folclore e da medicina tradicional dos povos indígenas é um meio eficiente para encurtar o caminho que vai desde os organismos silvestres a um produto comercial. Cita 0 argumento incontestável de que, dos 119 compostos farmacêuticos puros conhecidos sendo usados em alguma parte do mundo, 88 foram descobertos "através de dicas da medicina tradicional".

Embora farmacopéias científicas e populares listem múltiplos zooterápicos ${ }^{27}$, o emprego mé dico e etnomédico de animais ainda permanece como um "fenômeno semi-oculto" na literatura científica, sendo na maioria das vezes omitido pelos informantes de "folk" quando dos primeiros contatos com os pesquisadores, devido, dentre outras possíveis razões, a implicações legais (e.g., proibições à caça e consumo de animais nativos). Sabe-sehoje, entretanto, que o percentual de fontes animais para obten ção dos fármacos essenciais é bastante significativo e não fica muito abaixo daquele das fontes vegetais. Dos 252 fármacos essenciais selecionados pela Organização Mundial de Saúde, 11,1\% têm origem vegetal e $8,7 \%$, animal ${ }^{28}$.

Um grande número de pesquisas científicas vem dando suporte à eficácia terapêutica de animais, que, desde há muito, têm utilização popular. 0 potencial de utilização terapêutica de produtos da pele de rãs e sapos, por exemplo, vem encontrando, através da pesquisa farmacológica, avaliação positiva e crescente nas últimas décadas, revelando pequenos peptídeos dotados de atividades hormonais, psicotrópicas ou antibióticas ${ }^{29} . \mathrm{Na}$ herpetofauna brasileira, tanto a cascavel (Crotalus sp.) quanto a jararaca (Bothrops sp.) têm tido os seus venenosfarmacologicamente pesquisados. $\mathrm{Da}$ segunda foram patenteadas, no exterior, substâncias que compõem conhecidos agentes anti-hipertensivos comercializados no Brasil.

Outro destaque merecido tem sido dado às gorduras. Da mesma forma que autores têm destacado a importância das gorduras (banhas) na medicina popular em todo Brasil (e.g., I lha Gran- de, R ${ }^{30}$; Barra do Superagüí, $P R^{31}$; para Boa V ista, $R R^{32}$ ), o potencial terapêutico degorduras animais vem sendo amplamente discutido na literatura científica ${ }^{33,34}$. Atualmente, um dos produtos deorigem animal mais recomendados na alimentação humana é o ácido docosahexaenóico (DHA), um dos ácidos conhecidos como ômega 3. Cientistas reforçam o potencial profilático ecurativo ${ }^{35-37}$ do produto para uma gama variada de problemas, destacando-se: ação preventiva em relação à doença de Alzheimer; potencial para melhorar a visão de pessoas com dislexia; prevenção de doen ças coronarianas e aterosclerosee como coadjuvanteno tratamento da artrite, asma e esquizofrenia. 0 produto tem encontrado múltiplas indicações, parecendo mais um daqueles "remédios que servem para tudo". Diante da tão ampla gama de prescrições e usos populares, caberia inquirir sobre a razão do porquê fazêlo: estaríamos diante de medicamentos "ômnibus" que para nada serviriam ou de pelo menos uma possibilidade real para curas?

Valeressaltar que pesquisas realizadas no Brasil na última década encontraram o $\mathrm{DH} \mathrm{A}$ em gorduras de peixes nativos, quando sua ocorrência era atribuída exclusivamente a peixes de águas geladas e profundas ${ }^{38}$. Assim sendo, embora se deva levar em conta a não sobreposição total entre as relações decausa/efeito atualmenteapontadas pela investigação científica e as tradicionalmente citadas, vale a pena abdicar dos preconceitosedas ideologias em uma época quevêdoenças surgirem e ressurgirem (a exemplo da AIDS e da tuberculose multirresistente). Além do mais, situações deemergência (a exemplo deguerras, ações terroristas e catástrofes naturais) serão melhor enfrentadas com a disponibilidade de recursos locais e independentes da gl obalização.

As observações feitas neste trabal ho, embora de caráter mais especulativo, sugerem a possibilidade de que a medicina popular evolua não apenas como conseqüência de uma aprendizagem decorrente de uma sucessão de erros e acertos: é provável que nas teorias contidas no uso de "medicamentos" resida a capacidade de adaptação da medicina popular, no momento queum grupo migrante necessita incorporar espécies novas ( pela ausência das anteriormente utilizadas) à sua farmacopéia. Esta discussão merece aprofundamento, junto com a busca de possíveis padrões para a crença popular na eficácia terapêutica de produtos animais usados tradicionalmente no Brasil. 


\section{Colaboradores}

FBP M oura foi responsável pela tese de doutorado na qual se baseou este artigo e JGW M Mrques foi seu orientador.

\section{Agradecimentos}

A primeira autora agradece a toda população do Remanso, em especial ao Agente de Saúde $\mathrm{N}$ atalino N ascimento pela valiosa colaboração no acesso ao campo, pela ajuda na análise de dados e pela solidariedadedurante os oito meses de campo necessários a pesquisa para realização da tese.

\section{Referências}

1. Lages-Filho J. A medicina popular em Alagoas. Separata dos Archivos do Instituto Nina Rodrigues 1934; $3(1$ e 2$)$.

2. Lo Curto A. Gli animali che curano secondo la medicina indigena dell'Amazzonia. Roma: U niversale Electa/Gallimard; 1990.

3. Figueiredo N. Os bichos curam: os animais na medicina de folk em Belém do Pará. Bol. Mus. Paraense Emílio Goeldi. Série Antropologia 1994; 10:75-91.

4. Costa RPC, Silva WG. Medicina popular da Amazônia brasileira I: identificação dos ácidos graxos e triglicerídeos da banha da cobra sucuriju (Eunnects murinus). Revista da Universidade do Amazonas (Série Ciências da Saúde) 1993: 2.

5. Begossi A, Braga FMS. Foods Taboos and Folk Medicine among Fishermem from the Tocantins River (Brazil). Amazoniana 1992; 12:101-118.

6. Marques JGW. Pescando pescadores: etnoecologia abrangente no Baixo São Francisco alagoano. São Paulo: NUPAUB/ USP: 1995.

7. Souto FJB, Silva CS, Souza AF. U ma abordagem etnoecológica sobre a medicina popular em Andaraí, Chapada Diamantina, Bahia, Brasil. In: Anais do I Simpósio Estadual de Etnobiologia e Etnoecologia, 2000; Feira de Santana.

8. Almeida CFR, Albuquerque UP. Uso e conservação de plantas e animais medicinais no estado de Pernambuco (Nordeste do Brasil): um estudo de caso. Interciência 2002; 27(6):276-285.

9. Silva M LV, Alves AGC, Almeida AV. A zooterapia no Recife (Pernambuco): uma articulação entre as práticas e a história. Biotemas 2004; 17(1):95-116.

10. Posey DA. Etnobiologia: teoria e prática. In: Ribeiro D, organizador. Suma etnológica brasileira. Vol. 1. Etnobiologia. Petrópolis: Vozes/Finep; 1987. p.15-25.

11. Hays TE. An Empirical M ethod For the Identification of Covert Categories in Ethnobiology. American Ethnologist 1976; 3:485-507.

12. Queiroz MS. Hot and Cold Classification in Traditional Iguape M edicine. Ethnology 1984; 23(1):63-72.

13. Morgado P. O pluralismo médico Wayana-Apari. Cadernos de Campo 1994; 4:41-69.

14. Voeks R. Candomblé Ethnobotany: African M edicinal Plant Classification in Brazil. J. of Ethnobiology 1995; 15(2):257-280.

15. Voeks RA. Sacred leaves of candomblé. African magic, medicine and religion in Brazil. Austin: University of Texas Press; 2003.

16. Moran E. A ecologia humana das populações da Amazônia. Petrópolis: Vozes; 1990.

17. Marketos SG. Hippocratic M edicine and Nephrology. American Journal of Nephrology 1994; 14:264-269.

18. Petrucelli RJ. II. M onastic Incorporation of Classical Botanic M edicines Into the Renaissance Pharmacopeia. American Journal of Nephrology 1994; 14(4-6):259-263.

19. Gong X, Sucher N. Stroke Therapy in Traditional Chinese Medicine (TCM): Prospects For Drug Discovery and Development. TIPS 1999: 20.

20. Laderman C. Symbolic and Empirical Reality: A New Approach To the Analysis of Food Avoidances. American Ethnological Society Review 1981; 8(3):468-492. 
21. Ankli A, Sticher O, Heinrich M. Medical Ethnobotany of the Yucatec M aya: Healer's Consensus as a Quantitative Criterion. Economic Botany 1999: 53(2): 144-160.

22. Costa-N eto E. Barata é um santo remédio. Introdução à zooterapia popular no Estado da Bahia. Feira de Santana: UEFS; 1999.

23. Thé APG, Madi EF, Nordi N. Conhecimento local, regras informais e uso do peixe na pesca do altomédio São Francisco. In: Godinho HP, Godinho $A L$, organizadores. Águas, peixes e pescadores do São Francisco das M inas Gerais. Belo Horizonte: PUC M inas; 2003.

24. Holanda SB. Caminhos e fronteiras. São Paulo: Companhia das Letras; 1984.

25. Cox PA, Balick MJ. The ethnobotanical approach to drug discovery. Scientific American 1994; 270(6):8287.

26. Wilson EO. Diversidade da vida. São Paulo: Companhia das Letras; 1992.

27. Elisabetsky E, Nunes DS. Ethnopharmacology and its role in third world countries. Ambio 1990; 19(8):419-424

28. Korokolvas A. Planejamento de fármacos. Ciência e Cultura 1989; 41(6):528-537.

29. Amiche A, Delfour A, Nicolas P. Les trésors de la peau dês frenouilles. La Recherche 1996; 291:72-77.

30. Seixas CS, Begossi A. Ethnozoology of fishing communities from Ilha Grande. (Atlantic Forest Coast, Brazil). Journal of Ethnobiology 2001; 21(1):107-135.

31. Fernandes-Pinto E. Etnoictiologia dos pescadores da Barra do Superagüi, Guaraqueçaba/PR: aspectos etnotaxonômicos, etnoecológicos e utilitários [dissertação]. São Carlos (SP): UFSCar; 2001.

32. Pinto AAC, Maduro CB. Produtos e subprodutos da medicina popular comercializados na cidade de Boa Vista, Roraima. Acta Amazônica 2003; 33(2):281-290.

33. Dry JVD. Effect of a fish oil diet on asthma: results of a 1-year double-blind study. Int Arch Allergy Appl Immunol 1991; 95(2-3):156-157.

34. Eastman P. New Data on Influence of Vascular and Lifestyle Risk Factors on Alzheimer Disease Progression. Neurology Today 2007; 7(15):32-38.

35. M cDonald CV. Effect of fish-oil derived omega- 3 fatty acid supplements on asthma control. [abstract]. Aust N Z J Med 1990; 20:526.

36. Horrocks LA, Yeo YK. Health benefits of docosahexaenoic acid (DHA). Pharmacol Res 1999; 40(3):211-225.

37. Mahadik SP, Evans DR. Essential fatty acids in the treatment of schizophrenia. Drugs of Today 1997; 33(1):5-17.

38. Adeodato S, Leite M. Talento cearense: Universidade em Fortaleza cria produtos surpreendentes com matérias-primas regionais. Globo Ciência 1995; 42:62-65.

Artigo apresentado em 06/01/2007

Aprovado em 01/11/2007

Versão final apresentada em 30/11/2007 